\title{
De la guerrilla a las fábricas. Oposición al franquismo del Partido Comunista de España (1948-1962)
}

\author{
DAVID RUIZ *
}

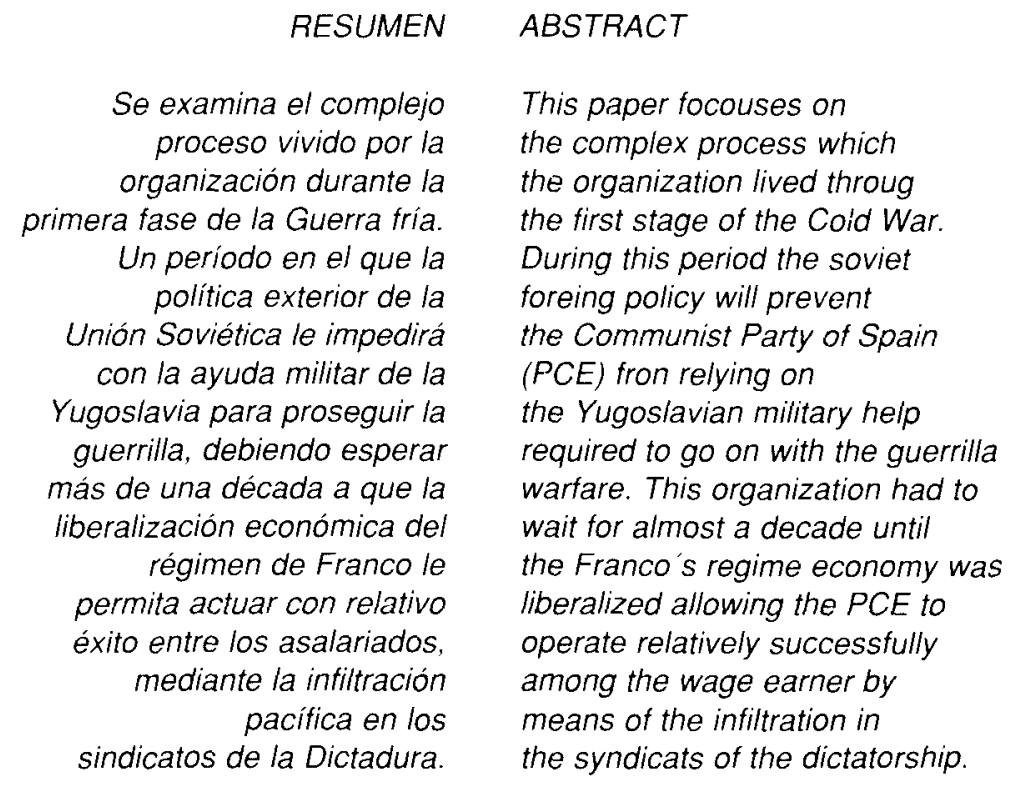

"Stalin tenía razón...", había llegado el momento de abandonar la lucha armada en las diversas cordilleras y macizos de la Península Ibérica

* Universidad de Oviedo. 
y, como hicieran los bolcheviques en los tiempos del zarismo, actuar en la organizaciones de masas para derrocar el régimen Franco.

A esta conclusión llegaría la dirección del PCE en el exilio a finales de la década del cuarenta después de que una reducida delegación de la misma compuesta por la secretaria general Dolores Ibarruri y los miembros de Buro Político, Santiago Carrillo y Francisco Antón, se entrevistaran en el Kremlin con el máximo dirigente de la Unión Soviética a finales del verano de 1948, tal como los dos primeros lo testimoniaran más tarde en sus respectivas Memorias. Reunión en la cumbre del PCE-PCUS, la primera y única de la que hasta hoy se tiene noticias entre ambas direcciones, celebrada casi una década después del final de la Guerra Civil española y más de un lustro de la disolución de la Komintern, pero no publicada hasta un cuarto de siglo después, en la fase eurocomunista, por el entonces secretario general Santiago Carrillo en un libro-entrevista publicado en Francia (Mañana España, París 1974). Singular acontecimiento que será refrendado en 1984 por Dolores Ibarruri y de nuevo por Santiago Carrillo en 1993, en sus respectivas Memorias.

$\mathrm{Ni}$ que decir tiene que la importancia y las circunstancias que rodearon el encuentro del Kremlin en el que Stalin estuvo acompañado por Molotov, Suslov y Voroshilov, ha hecho de él una referencia controvertida. Y ello no tanto por haberse omiuido su celebración más allá de la dirección del partido durante tantos años, decisión en cierto modo compresible por el uso que enemigos y adversarios del PCE hubieran hecho de él en la más aguda fasé de la guerra fría, como por la relación de causa a efecto con la entrevista de otra delegación del PCE encabezada por Enrique Lister con el mariscal Tito en Belgrado en la primavera del mismo año 1948 en demanda nada menos que de ayuda militar para reforzar la lucha contra Franco; concretamente para solicitarle el envio de fuerzas paracaidistas a la Agrupación guerrillera de Levante.

Un encuentro este último que se produjo justamente en el momento que la crisis yugoslava abría la primera grieta en el Bloque de paises del "socialismo real", fisura de la que aún no tenían noticia los dirigentes españoles pero si los soviéticos de la visita a Belgrado de la delegación del PCE; motivación más que suficiente para que los soviéticos demandaran la presencia en el Kremlin de la representación citada con el presumible propósito de verificar la permanencia de la fidelidad del PCE a «la casa», a Moscú, frente al titismo emergente. $Y$ que una vez garantizada la adhesión, resulta verosímil que en conversación más distendida Stalin les aconsejara sobre la conveniencia de abandonar la guerrilla y ensayar la alternativa antes citada, además de concederles una discreta ayuda económica 
De la guerrilla a las fábricas. Oposición al franquismo del Partido Comunista...

a aquellos españoles siempre orgullosos y reacios -Stalin dixit, según Carrillo- a aceptar el "oro de Moscú».

Que a la Unión Soviética le interesaba menos entonces la España de Franco que la Yugoslavia de Tito e incluso que ésta se subordinaba a una estrategia más global, es una hipótesis que tiende a reforzarse con el conocimiento de nuevos datos relacionados con el creciente enfrentamiento bipolar de finales de los cuarenta en el que nada menos el gobierno ruso barajó la posibilidad por parte del sector del PCUS más próximo a Stalin, de una respuesta militar a la ofensiva ideológica antisoviética recién desencadenada por los Estados Unidos. Perspectiva que para su ejecución debería implicar el respaldo y la eventual participación los comunistas occidentales, incluídos los partidos clandestinos peninsulares, el español y portugués, según la documentación ya accesible de los archivos soviéticos recientemente consultada ${ }^{1}$. Primer riesgo, pues, de estallido de la tercer guerra mundial que no se disipará hasta unos años después tras el armisticio del conflicto coreano y la muerte de Stalin en 1953.

En cualquier caso dando por seguro que la principal preocupación de la dirección del PCE era la de sobrevivir para volcarse sobre España, cabe preguntarse sobre la suerte corrida por la recomendación del líder soviético a sus camaradas españoles sobre la conveniencia de «entrar» en las organizaciones de masas. De manera principal porque que si como también ha recordado Santiago Carrillo, Stalin les aconsejó «paciencia, mucha paciencia» para llevar a buen fin el objetivo, se tiene la impresión de que los dirigentes españoles lo cumplieron a rajatabla. Porque de otro modo resulta chocante en un partido tan supuestamente disciplinado como el PCE, el considerable retraso registrado en el abandono de la guerrilla. Más aún si entre la militancia implicada se conocía la singular procedencia política de la consigna, - como muy probablemente debió entenderse la sugerencia staliniana sobre la que poco tiempo después reflexionaria el propio Santiago Carrillo en un artículo de Nuestra Bandera $(n .31,1948)$ la revista teórica del partido, no en Mundo Obrero, sin citar la fuente lógicamente y sin excesivo convencimiento, en su condición de responsable de la organización del partido en el interior. Y ello porque hasta el abandono de las armas pasaron no solo meses sino años, continuando la actividad guerrillera con su correlato de enfrentamientos militares, "golpes económicos» «ajusticiamiento» de fascistas, represalias de las contrapartidas

E. Aga-RosI y V. ZASLAVSky: Togliatti e Stalin. II PCE e la politica estera staliniana negli archivi di Mosca. Bologna, 1997; págs. 248 y ss. 
franquistas, etc., hasta los comienzos de la década de los cincuenta según consta en la documentación de archivos del propio partido ${ }^{2}$.

Dramática prolongación de la guerrilla comunista más allá del deseo y la previsión de, al menos, una parte de la dirección y de la inmensa mayoría de los militantes del interior que debieron contemplar como tras el éxito de la evacuación de algunas decenas de supervivientes de la agrupación guerrillera socialista asturiana en el mismo año 1948, salida preparada por la dirección exterior del PSOE, las más numerosas y nutridas agrupaciones del PCE quedaban a merced de la persecución implacable de las fuerzas de seguridad franquista. Llegaron a ser miles los guerrilleros que siguiercn resistiendo aún después del otoño de 1948 hasta que la Guardia Civil y la policia franquista acabaron con los últimos grupos en 1952, dejando detrás de si tan alta tasa de mortalidad que también será contada por millares ${ }^{3}$.

Así pues una vez concluída la lucha armada parecía llegada la hora, al fin, de aplicar "creativamente» la doctrina Stalin o como se argumentará el cambio en la historia oficial del partido publicada en 1960, retomar «la táctica leninista con suficiente energía " ${ }^{4}$ en el trabajo político, en la nueva realidad sociolaboral de la España franquista. Difícil tarea la que se les avecinaba dado que al régimen de Franco le beneficiará la coyuntura internacional de la guerra fría en la misma medida al menos que perjudicaba al PCE. Y a nivel interno el gobierno franquista suprimía en 1952 la cartilla de racionamiento, coincidiendo prácticamente con el fin de la guerrilla y el comienzo de un crecimiento económico que le llevaría, - tras los años del hambre, del mercado negro, la "pertinaz sequía» y el aislamiento internacional de los cuarenta- a la recuperación por parte de los asalariados de la capacidad adquisitiva de la inmediata preguerra. $Y$ finalmente porque a la oposición le esperaba nada menos que el acuerdo recién firmado de Franco con el gobierno norteamericano en 1953, espectacular respaldo a la más importante dictadura europea superviviente de los fascismos derrotados en 1945 por parte de la ya indiscutible primera potencia entre las democracias capitalistas. Una situación que para colmo de la adversidad favoreció que los compañeros socialistas les prosiguieran marginando de cualquier alianza antifranquista habida o por haber desti-

2 AHCCPCE, Madrid. «Resumen de la lucha guerrillera en España de 1945 a 1950» en MGG, carp. 2.

F. Moreno, en S. Julia, coord. Victimas de la Guerra Civil. Madrid, 1999.

Dolores lbarrufi, coord. Historia del Partido Comunista de España, París, 1960; págs. 236 238. 
nada a la recuperación de la democracia, por su condición de «partido totalitario" - según una contundente resolución del VI congreso del PSOE en el exterior en 1954- justamente cuando la politología norteamericana acuñaba la noción de «régimen autoritario», es decir, de no fascista, que años después Juan Linz ensayaría su aplicación al caso español.

Ciertamente los estragos causados al PCE desde y por el estallido de la guerra fría parecían no tener fin desde el punto y hora que mientras el enfrentamiento bipolar permitía a Franco salir del aislamiento y al dictador enarbolar de nuevo la vieja bandera del final de la Guerra Civil reclamando para sí la vanguardia en la defensa de la civilización contra el peligro bolchevique, a los comunistas españoles les conduciría al ostracismo político más acusado de su historia. Por no tener aliados, ni siquiera podían contar con un respaldo sindical afín aunque minoritario, como la CGTU de los tiempos republicanos, por ejemplo, porque la militancia en la esfera laboral la habían compartido con los socialistas en la UGT desde 1935 y ésta, siguiendo al PSOE, se insertaba también en la órbita anticomunista. ¿Qué hacer, pues, en aquella difícil situación en la que además en 1950 la dirección y la militancia más activa eran expulsadas de Francia y con Stalin moribundo?

Acudir, en primer término, al entierro de Stalin, circunstancia que brindó a la errante dirección la oportunidad de reunirse en Moscú no solo para asistir a las honras fúnebres y expresar su condolencia por la desaparición del "dirigente probado en mil combates», sino también para intercambiar experiencias multiples acumuladas desde la salida al exilio y propiciar la reflexión en grupo sobre lo acontecido a la organización desde 1939. Muy probablemente sin destacar los delicados y graves problemas surgidos en la organización antes y después de que a finales de los cuarenta, en diciembre de 1949, apareciera en Mundo Obrero la después difundida consigna estalinista referida a que "el partido se fortalece depurándose de los elementos oportunistas". Y de que en ese tiempo se disparase la paranoia iniciada en Moscú tras la muerte José Díaz en 1942 y el acceso de Dolores Ibárruri a la secretaría general del PCE, alimentándose después con las dramáticas vicisitudes de la lucha contra Franco en la que los casos de Herberto Quiñones, Jesús Monzón, y Joan Comorera sobresaldrán por su significación en cuanto expulsados de la organización tras ser acusados de actividades fraccionales y/o "desviación titista», motivo éste aducido para la marginación del por otra parte convicto stalinista, Joan Comarera, en 1949. Extrema dureza del contexto de guerrilla y guerra fría que se advertía aún en los años finales del estalinismo oficial dado que los desmantelamientos habidos en las organizaciones del interior provocadas por la infiltración de la policia franquista, proseguían sin cesar. 
No obstante a comienzos de los cincuenta ya se tendió a bajar la guardia ante el enemigo interno y dejaron de infundir sospechas al aparato quienes habían logrado salir con vida de los campos de exterminio nazis, como mostró el caso de Jorge Semprun quien poco tiempo después de ingresado en el partido compartirá con el veterano Rafael Alberti la autoría de la creación literaria más respetada por el conjunto de la organización, la de las loas poéticas destinadas a honrar la memoria de Stalin, "guía de los pueblos y de los trabajadores del mundo...". Pero transcurririan años antes de disiparse los recelos ante camaradas salidos de las comisarías de la policia franquistas y las cautelas de las células ante los nuevos ingresos 5 .

Debió ser en aquélla tesitura, en aquel breve período de «tiempo muerto" cuando enterrado Stalin y confirmado que los esperanzadores acontecimientos del boicot a los tranvias y la huelga que le siguió en la Barcelona de 1951, desafortunadamente para la oposición, no tuvieron prolongación mientras el régimen de Franco parecía consolidarse, cuando la dirección del PCE acordó organizar el $V$ congreso. Celebración que tendrá lugar después de más de dos décadas del reunido en Sevilla en 1932, (en el que el ex-cenetista José Díaz fue elegido secretario general tras ser arrojado a las catacumbas el denostado (grupo Bullejos») cerrando al fin uno de los más prolongados paréntesis intercongresuales registrados en la historia universal de los partidos políticos no confesionales. Circunstancias atenuantes que aducir no faltaron a la dirección, de manera principal el hostigamiento de que fue objeto a causa de la prioridad dada a la lucha militar contra el fascismo en España y Francia, a través de una ininterrumpida larga marcha iniciada en octubre de 1934 y no concluída hasta dieciocho años después con la liquidación de la guerrilla. Excusa de grueso calibre, sin duda, pero que no sería aceptada como única ni siquiera por todos militantes de la organización de la época.

$Y$ sin embargo los resultados del $V$ congreso no se correspondieron con las expectativas generadas porque después de prolongada travesía apenas se produjeron cambios. No obstante el hecho de haberse reunido tras la muerte de Stalin y presumiblemente cuando Nikita Jruschov aún se hallaba incorporando datos al devastador informe que presentara dos años después, en 1956, ayuda a explicar el balance escasamente novedoso que ofreció. Esa fue la percepción que propios y extraños tuvieron de la aprobación en él de la táctica del Frente Nacional antifranquista que además de derribar la dictadura de Franco, contemplaba la

5 D. GINARD I FERON, L'Oposició antifranquiste i els comunistes mallorquins (1939-1977). BarCelona, 1998, pág. 49. 
convocatoria de elecciones a cortes constituyentes para decidir la forma del Estado. Tampoco constituyó un hallazgo sino cierta rémora que en el diagnóstico de la situación económica de la España del momento se detectara aún la presencia de "supervivencia feudales" en el sector agrario, en extraña coexistencia al parecer con el capitalismo monopolista ya predominante.

En cambio la cúpula dirigente del partido salió fortalecida del congreso. No tanto por la participación de la delegación mexicana, -lejana y encomiable pero también poco activa e incluso problemática-como por la asistencia de una representación no elegida, obviamente, de la española del interior que logró burlar la vigilancia policial franquista, pasar a Francia y presentarse en Praga. En ella figurará el obrero panadero madrileño Simón Sánchez Montero con méritos más que sobrados ya entonces para ser elegido miembro del comité central, y un reducido grupo de profesionales cuya sola presencia surtirá efectos casi mágicos al simbolizar los comienzos de la apertura del todavía "único partido de la clase obrera", -el marxista-leninista-stalinista, por supuesto- a los intelectuales y categorías sociales no estrictamente asalariadas. El escritor Jorge Semprún, también elegido entonces para el comité central, se responsabilizaría orgánicamente de la incorporación al partido de este sector en el que se advertían posiciones críticas cuando no abierta hostilidad al régimen de Franco; disidencia que la pasividad de republicanos y socialistas facilitó su acercamiento a las posiciones antifranquistas del PCE. Nueva e interesante perspectiva que se abría a partir de aquel congreso, capaz de relegar a segundo plano y silenciar el sorprendente análisis de la secretaria general, Dolores Ibárruri, quien en su informe sobre el momento político de España se interrogó si el acuerdo hispanonorteamericano firmado el año anterior, 1953, además de constituir un delito de "dimisión nacional», no era también una muestra de debilidad y no de fortaleza del régimen de Franco por necesitar apoyos externos para sobrevivir. La misma dirigente que una década después, ya en su condición de presidenta del partido, valorará como propio de «intelectuales cabezas de chorlito" la posición mantenida por Jorge Semprún y Fernando Claudín en la crisis de los setenta.

Aunque visto desde la perspectiva actual el $\mathrm{V}$ congreso referencia el embrión de la futura alianza de las «fuerzas del trabajo y la cultura", la preocupación central pasaba por priorizar la militancia en la esfera laboral sin abandonar la organización territorial. Tarea tan necesaria la constitución de células en los centros de trabajo como urgente era la de crearlas de nueva planta en los escenarios anteriormente de guerrilla, como por ejemplo la constitución del comité provincial de Asturias que no se logró 
hasta mediados de $1955^{6}$. O en el extremo opuesto, alentar y proteger actividades como la desplegada desde comienzos de la década por un reducidísimo número de militantes que en el confín meriodional de Andalucía logró organizar a los viticultores del Marco de Jerez y utilizar con tanta resolución como sabiduría la normativa legal franquista para obtener mejoras retributivas y laborales para los jornaleros agrícolas, que un estudioso del fenómeno creyó ver en ellos a «los verdaderos artífices de la democracia española» 7 .

Una utilización de las posibilidades legales adaptada a las condiciones concretas de la gran propiedad agraria exportadora que encontró obstáculos inferiores al practicado por sus camaradas en las zonas industriales al coincidir con la reciente desaparición de los enfrentamientos guerrilleros. En cualquier caso el cambio que suponía en las fábricas y minas del norte y catalanas renunciar a las reclamaciones individuales reglamentariamente previstas, y plantear reivindicaciones colectivas significó que en la década de los cincuenta la infiltración de la policía en comités de fábrica, iocales y regionales del PCE ( $y$ en mucha mayor medida en los que quedaban de la CNT) superó con creces la táctica inversa, es decir, la recomendada por Stalin en la famosa entrevista de 1948.

Tal como se ha aludido anteriormente, fueron numerosas las desarticulaciones de órganos de dirección - regional asturiana, por ejemplo, lo fue nada menos que en cuatro ocasiones entre 1952 y $1961^{8}$ y bastante frecuente la participación de compañeros de trabajo en calidad de confidentes de la policía a los que ésta brindaba movilidad laboral al concluir su misión ${ }^{9}$; los detenidos acababan en las cárceles previo paso por los interrogatorios en ias comisarías en las que las torturas era la norma, en absoluto la excepción, en aquel período. Procedimiento policiaco que se reveló de extraordinaria eficacia para obtener información dada la absoluta impunidad jurídica en que la represión se desarrolló. Entre los represaliados el protagonismo lo asumía la minoría heróica, la de los comunistas auténticamente "probados" por resistir la tortura -en algún caso hasta la muerte- sin dar nombres de compañeros implicados en la actividad clandestina. Preservar a toda costa la organización a la vez que manteniéndola en plena actividad se convirtió en el motivo central del incremento de

\footnotetext{
6 R. Garcia Pineiro, en F. ERice, coord. Los comunistas en Asturias 1920-1982. Gijón 1996; págs. 147 y ss

J. Foweraker, La democracia española. Madrid, 1990.

P. Garcia Piñeiro en art cit.

9 J.R. Gómez-Fouz, Clandestinos. Oviedo, 1999; págs 32 y ss.
} 
la vigilancia y de la rigidez estatutaria del partido en todo lo concerniente a cuestiones disciplinarias.

Así y todo la tensión proselitista reapareció tras la traumática retirada de la guerrilla. Y si los resultados fueron más bien escasos se debió principalmente al miedo de la inmensa mayoría de los trabajadores a la represión dentro y fuera de las fábricas; y de forma secundaria a que la forma de actuar en éstas de los militantes se planteará esgrimiendo ante los compañeros la sigla del partido ante la ausencia de la de los sindicatos de clase históricos, UGT y CNT, en la brega cotidiana. Una modalidad de actuar en la que se insistió más tarde con la OSO (Organización Sindical Obrera) dependiente del partido repitiéndose los resultados porque cambiaba la sigla pero esgrimida por los mismos comunistas. Ni siquiera hará progresos en el Madrid del desplegue industrial al final de la década, pese a la decisión preferente de que fue objeto en la capital, a juzgar por el testimonio del militante del PCE y principal promotor de las Comisiones Obreras desde comienzos de los setenta ${ }^{10}$.

Parecía pues con cierta evidencia que la España de Franco en los cincuenta no era, a los efectos de la lucha obrera, homologable a la Rusia del último zar en la que se forjaron los soviets, tal como al parecer los recordó Stalin en 1948. Las mayores movilizaciones contra el régimen en lugar de producirse a consecuencia de la reuniones de célula y del "tacto de codos" en los tajos procederán de boicots ciudadanos, como el realizado en Barcelona a la utilización de los tranvías por amplísimos colectivos en febrero de 1951. Cierto fue que tras la acción interclasista en las calles de la ciudad se registrará una movilización estrictamente obrera de envergadura, en la que el activismo de los militantes del PSUC fue notable. Pero cuando el PCE proyectó repetir la situación en Madrid, la llamada a la no utilización de los transportes urbanos apenas tuvo seguimiento quedando inédita en consecuencia la segunda fase del proceso, la huelga obrera ${ }^{11}$.

Insistencia de nuevo en verificar la incidencia de la "doctrina Stalin» tras aceptar la participación en las elecciones sindicales en 1954 -las anteriores las habría rechazado la militancia con tanta repugnancia como la socialistay definitivamente distanciarse de la UGT en el mismo año de la celebración del $V$ congreso. $Y$ el anterior al que celebró la Organización Sindical Española, la OSE, en el que no sin cierta sorpresa los verticalistas del régimen ofertarán salario mínimo, disminución de la jornada, equiparación retributiva

10 M. Camacho, Confieso que he luchado. Memorias, Madrid, 1991 ; pág. 150.

1 J. BABIANO, Emigrantes, cronómetros y huelgas. Un estudio sobre el trabajo y los trabajadores durante el Franquismo (1951-1977); págs. 204-231. 
entre los sexos y seguro de paro, en gran parte incluidas en las reivindicaciones programáticas del congreso de los comunistas. Calculada estrategia de los jerarcas del Vertical destinada a integrar a los asalariados en el régimen como no se recordaba desde los ya lejanos tiempos bélicos con Gerardo Salvador Merino. Campaña que incidió sobre las ventajas del nacionalismo económico, del sindical, y de la nueva justicia social, con la intención de rentabilizar el crecimiento económico de los tres últimos años y el éxito internacional de la admisión de España en la ONU en ese mismo año de 1955. Años también en los que si en términos generales la situación había experimentado una mejora, los trabajadores de la industria seguían siendo mayoritariamente hostiles al régimen y su organización sindical. Y los cuadros dirigentes conocian esta actitud; y gracias a recientes investigaciones y la apertura de nuevos archivos hoy ya sabemos que lo sabían ${ }^{12}$.

Sin embargo ni el gobierno con su programa de mejora garantizó la estabilidad ni la actuación del partido comunista fue determinante de las huelgas registradas en el bienio 1956-57 en Cataluña, Euskadi y Asturias, principalmente, las de mayor importancia desde la guerra civil, en las que la reivindicación salaria! figuró como objetivo central, y casi único, entre los movilizados. Y ello fue asi porque el crecimiento económico había generado un proceso inflacionario tal que parecía correrse el riesgo de retornar a los años del hambre por la pérdida de la capacidad adquisitiva. Situación en gran medida por la permanencia del reglamentarismo y las trabas a la producción propias de la autarquía, a la que el ministro de Trabajo, Girón de Velasco, trató de poner remedio demagógicamente decretando contra viento marea, - contra los mismos patronos y los partidarios de una tímida liberalización- dos nuevas subidas salariales a lo largo de 1956. Ello no fue obstáculo para que las movilizaciones fueran entendidas en clave política por el gobierno en tanto que problema de orden público y grave delito por seguir la huelga severamente penalizada, y el gobierno procediera en consecuencia, esto es, a ejercer la represión y a cambiar la política económica. La autarquía dejaba paso a la liberalización económica y en la gestión de ésta los tecnócratas desplazaban a los falangistas. Con toda certeza ni unos ni otros eran conscientes de que aquella transición económica se completaría veinte años después con la política. Principalmente porque ninguno de los dos sectores la deseaba; ni entonces ni muy probablemente después, en 1977.

Que en el citado bienio 56-57 los comunistas fueran incapaces de conducir las movilizaciones dotándolas de mayor mordiente político no

12 P. YSÁs y C. MOLInERO, Productores disciplinados y minorias subversivas. Clase obrera y conflictividad laboral en la Esparia franquista. Madrid, 1998; págs. 26 y ss. 
De la guerrilla a las fábricas. Oposición al franquismo del Partido Comunista...

quiere decir que sus militantes no aspirarán ya a liderar las movilizaciones por economicistas que fueran. Ni tampoco que a lo largo y a lo ancho de las huelgas "meramente reivindicativas" renunciaran a utilizar siglas del partido y muchos arrojarán por la borda anteriores sectarismos estableciendo lazos descubriéndose repentinamente colaborando con trabajadores de otras ideologías, principalmente con católicos de la HOAC y la JOC renuentes a secundar las posiciones episcopales de la guerra civil entendida como "cruzada de liberación" sobre todo desde que en 1951 los obispos, obedeciendo fielmente al gobierno, les secuestran la revista Tú, del apostolado seglar, cuando había llegado a difundir cuarenta mil ejemplares. De ahí que fuera precisamente con ellos, ante la ausencia de la UGT -o si estaba presente su inadaptación a la clandestinidad era notoria - con los que se produjera una relación que no dejaron de tener importancia en la génesis y/o mantenimiento de los conflictos al margen del sindicato vertical; relación de comunistas y católicos sin la que no se explica el nacimiento multifocal e ideológicamente plurales de las primeras "comisiones de obreros" en diversos lugares del norte minero e industrial durante aquel período. Aparición, pues, de Comisiones, sino totalmente espontáneas si al margen del PCE e incluso con el agravante de la desconfianza hacia ellas de sectores amplios de la dirección por no ser el resultado del trabajo programado y, sobre todo, por su manifiesta propensión a disolverse una vez logrados sus modestos objetivos. Motivos suficientes ambos para no suscitar entusiasmos en la dirección a pesar de que esta convocara una reunión de cuadros en París en 1959 para debatir la temática correspondiente.

Mayor interés que las incipientes Comisiones despertará el alboroto estudiantil registrado en la universidad madrileña a comienzos de 1956. Agitación que contra muchos pronósticos acabará influyendo más que las huelgas obreras del bienio en el importante cambio estratégico que el partido comunista emprenderá el mismo año, el de la política de Reconciliación Nacional.

Consistió aquella en una tumultuosa protesta juvenil de la que no se conocian antecedentes desde las postrimerías de la dictadura de Primo de Rivera. Con la diferencia de que en los cincuenta la exigencia democratizadora de la institución universitaria pasaba por la supresión del sindicato estudiantil, el SEU. El rifirafe entre estudiantes demócratas y falanguistas que aún no se habian desilusionado del anquilosamiento burocrático de la organización concluyó, como es sobradamente conocido, con la destitución del mismo del ministro de Educación (Joaquín Ruiz Giménez) y de dos rectores universitarios, Laín Entralgo y Tovar, de la Complutense y Salamanca respectivamente. 
Un conflicto en el que se evidenciaron en cierta manera y a menor escala las dos tácticas experimentadas en acontecimientos como el de la Barcelona de los tranvías, la del boicot al encuadramiento obligatorio que representaba el SEU lo que significaba la eliminación de éste en la Universidad -comportamiento que predominó en la mayoría de las Facultades- y la perseguía la transformación democrática del sindicato "entrando" en él, participando en las elecciones y ganándolas como ocurrió en la de Derecho, antes de que la intervención policial lograra frenar la agitación. Pese a la imposibilidad de extender la protesta a otras universidades y la más impensable aún de prolongarla hasta hacerla coincidir con las huelgas obreras, el balance resultante se entendió satisfactorio para el partido. En primer lugar porque en aquella «revuelta de privilegiados» participaron en condición de tales por su extracción familiar el grupo de militantes del partido que en su mayoría, además, fueron detenidos, con el correspondiente efecto propagandístico que la represión a la disidencia no obrera tuvo dentro y fuera de España. En segundo término porque en la agitación estudiantil habían participado conjuntamente estudiantes vinculados PCE y de la Asociación Socialista Universitaria (ASU), reacia a compartir con la dirección del exterior PSOE la marginación de los comunistas. Y finalmente porque la rebeldía juvenil vigorizaría la hasta entonces testimonial oposición liberal —algunos como Dionisio Ridruejo antiguo colaborador de la dictadura fueron también detenidos contribuyendo a extender el antifranquismo entre profesionales e intelectliales-. De entre estos últimos pronto se significarían un grupo de poetas, cineastas y pintores, tanto por la crítica al régimen que ejercian en sus obras por su progresiva vinculación al partido comunista ${ }^{13}$.

Aunque acontecimientos internacionales de la envergadura del informe sobre el estalinismo de Jruschov en el XX congreso del PCUS y la pluralidad de vías al socialismo que a partir de él se contemplaron, tampoco pueden disociarse del «nuevo rumbo» que para el partido comunista supuso la adopción de la Reconciliación Nacional, la protesta estudiantil que acababa de concluir en Madrid, tal como se acaba de apuntar, resultó de más ayuda que la movilización obrera que acababa de empezar. Y ello se debió a que además de que el esfuerzo invertido por el partido en la Universidad fue de una rentabilidad politica muy superior al del sector industrial como lo

13 Ver, entre otros, M.A. Ruiz CARniCER, "Actitudes politicas, sociales y sindicales de los estudiantes universitarios españoles 1939-1960» en L Université en Espagne et en Amerique Latine du Moyen Age a nos jours. Vol I Tours, 1991; págs. 397-442. y F. Sevillano Calero, «Cultura propaganda y opinión en el primer íranquismo" en G. SÁNCHEZ RECIO, ed. El primer franquismo, 19361959. Madrid, 1999. 
prueba el haber provocado una crisis de gobierno -crisis que algunos optimistas creyeron del régimen- para algunos dirigentes del PCE fué más fácil que para otros discernir que los primeros efectos políticos del relevo generacional se habían manifestado antes en las facultades universitarias que en las fábricas. Distinta cuestión será el ulterior impulso del fenómeno pero hasta que tome cuerpo en los setenta, la importancia de la fecha de 1956 en la que por primera vez convergieron hijos de vencedores y vencidos exigiendo la democratización del régimen veinte años después del comienzo de la guerra civil, los acontecimientos universitarios de febrero pondrían en cuestión en el interior el inalterado discurso oficial de legitimación del régimen que los comunistas se disponian a formalizar.

El debate sobre la urgente necesidad de acabar con las dos Españas sobre la base de que las clases populares de los bandos enfrentados en la guerra civil fueron igualmente víctimas, apuntado en el pleno del comité central del PCE en Bucarest y celebrado en la Alemania Oriental, apenas encontró una oposición transitoria entre los más veteranos de los reunidos. Principalmente porque la propuesta además de entenderse como refuerzo a la estrategia del cambio pacífico hacia la democracia podía asumirse como táctica capaz, se creía, de debilitar el respaldo de masas que aún conservaba el régimen, independencia de que en ella se hubieran registrado cambios importantes desde el fin de la guerra civil.

$Y$ como los acontecimientos estudiantiles y obreros del bienio $56-57$ habían incrementado el malestar frente al régimen de otros sectores sociales, la dirección del partido estimará suficientes indicios para que el pleno de comité central reunido en septiembre del último año citado acordara la realización de una jornada por la Reconciliación Nacional concebida como culminación y convergencia de conflictos de diversos tamaño y origen con participación de ideologias de todo el espectro antioligárquico. $Y$ se dispusieron a realizarla sin otros aliados que los pequeños grupos de reciente creación tutelados por Dionisio Ridruejo, Enrique Tierno Galván y Julio Cerón, llamando a un día de paro y manifestaciones que programaron para el cinco de mayo de 1958. Los resultados de la Jornada por la Reconciliación Nacional en absoluto respondieron a las expectativas generadas; ni siquiera en Madrid donde la última imagen retenida por la militancia co munista había registrado un importante seguimiento al boicot a los transportes urbanos el año anterior, boicot que el gobierno no fue capaz de impedir pese al anticomunista e intimidatorio artículo "A ti trabajador" que Emilio Romero publicó el nueve de febrero de 1957 en el diario Pueblo. En fin, la jornada arrojó un balance según el cual la secundaron más los enclaves industriales clásicos que los más tardíos por registrarse prácticamente la única sorpresa en el Pais Valenciano en donde proliferaron los paros 
parciales en diferentes empresas llegandose incluso a la huelga general en el no menos clásico reducto alicantino de Alcoy ${ }^{14}$.

EI PCE había realizado la primera convocatoria política nacional el mismo año que en las cárceles franquistas volvían a rebosar de comunistas a consecuencia de la participación en las huelgas del bienio anterior en el penal de Burgos más de un millar de los 1.355 «residenciados»-, y en la misma primavera que el gobierno franquista promulgaba la Ley de Convenios Colectivos que suponía el fin de una también larga época de intervencionismo y reglamentismo autárquico y el comienzo de una nueva fase en la historia de las relaciones laborales del régimen. Normativa ésta que perseguía la liberalización controlada de la negociación obrero-patronal en la perspectiva del incremento de la productividad, operación que se insertaba en el plan estabilizador previo programado por los tecnócratas. Circunstancia que a su vez implicaba una reducción retributiva de los operarios como consecuencia de la supresión de las horas extraordinarias y otros pluses cuando no el despido. En fin, se diseñaban los sacrificios sociales precisos para el "despegue" económico a la vez que se abría la espita a la emigración en busca de trabajo a la próspera Europa del incipiente comunitario. ¿Era propicia esta coyuntura para llamamientos a la acción nacional por la reconciliación política marginando entre los objetivos reivindicaciones de tipo económico?

Sin embargo el ensayo se repitió en junio de 1959, un año después del primero bajo la rúbrica de Huelga Nacional Pacífica (HNP) ante las fundadas previsiones de participación de nuevas organizaciones adheridas a la convocatoria, como asi fue. De manera especial en Cataluña en donde junto a la participación de la sección catalana del Frente de Liberación Popular (FLP), se añadió el movimiento socialista (MSC). Situación que a pesar de que la dirección del PSOE-UGT de nuevo se mantuvo al margen de la convocatoria la adhesión de las nuevas siglas colocaron al PCE en el trance de salir del aislamiento político al que había sido condenado desde el fin de la guerra civil ${ }^{15}$.

Claro está que el acuerdo de unidad para la HNP no figuraría en documento alguno firmado por las diferentes organizaciones dejando en las del interior una imagen del partido obsesionado por no perder el control del pro-

\footnotetext{
14 J. Soler e I. SAZ, en D. Ruiz, dir. Historia de Comisiones Obreras, Madrid, 1993; págs. 293294.

is Ni autoría ni contenido se ajustan a la características que asigna P. ANDERSON a este tipo de relatos en "La historia de los partidos comunistas" en R. SAMUEL, ed. Historia popular y teoria socialista. Barcelona, 1984; págs. 151-156.
} 
De la guerrilla a las fábricas. Oposición al franquismo del Partido Comunista..

yecto y su realización. Impresión que no facilitará las relaciones posteriores, máxime cuando los resultados del segundo intento fueron menos satisfactorios aún que los del primero; y peor aún cuando la represión del gobierno de los tecnócratas actuó a la hora de las detenciones de dirigentes con celo que no desmereció respecto del de sus antecesores falangistas.

Sí se había logrado ampliar la difusión del mensaje de la Reconciliación Nacional pero en un momento en que la preocupación de la inmensa mayoría de la población continuaba siendo el mantenimiento del puesto de trabajo, la retribución salarial y ya para centenares de miles la perspectiva emigratoria. Adversa coyuntura para, a corto plazo, confiar en movilizaciones masivas según el formato de las planteadas; preferible la espera sin bajar la guardia organizativa y sin retroceder en el frente obrero que a la vista de lo acontecido, precisaba refuerzos. Objetivo éste que sería abordado en el mismo año 1959 en una reunión de cuadros políticos y sindicales en la «banlieue» parisina, a la que aludimos anteriormente. $Y$ mientras tanto, en espera de nuevos acontecimientos, distribuirse el trabajo entre una tarea tan especial como la redacción de la historia de la organización y la más convencional de preparar la celebración de un nuevo congreso.

¿Para qué una historia del partido en aquellas condiciones a la que se hallaba sometido? Para facilitar a militantes y simpatizantes "y en particular a los jóvenes que en los últimos tiempos acuden a nuestras filas" el conocimiento del pasado de la organización incluyendo aciertos y errores y neutralizar la incesante propaganda de sus enemigos, se esgrimirá en la versión española que vió la luz en París (Imprenta Hermel) a primeros de agosto de 1960, es decir, después de concluir el VI congreso del partido.

Efectivamente una comisión de dirigentes de la organización presidida por Dolores Ibárruri en la que figuraron Manuel Azcárate, Luis Balaguer, Antonio Cordón, Irene Falcón y José Sandoval se hizo cargo de la redacción de esta singular historia oficial que comprende los cuarenta años hasta entonces trascurridos desde la fundación 1920. Entre otros muchos extremos se argumenta el nacimiento en los ecos finales del "trienio bochevique" como "fruto de la necesidad histórica de la sociedad española y del movimiento obrero"; se describen vicisitudes y se trazan contextos en los que cobran coherencia interna los cambios tácticos y estratégicos adoptados, cobran protagonismo los años de la guerra civil -a la que posteriormente la dirección dedicará tres volúmenes-y se silencian hechos como el ya aludido concerniente a la entrevista con Stalin ${ }^{16}$.

16 A. MATEOS, EI PSOE contra Franco (1953-1974). Madrid, 1993; págs. 159 y ss. 
La publicación de este libro, de indiscutible interés historiográfico independientemente de enfoque, tratamientos, presencias y omisiones $-\mathrm{y}$, por supuesto, también por ellas- debió estar lista cuando se iniciaba el VI congreso. $Y$ éste se celebró en un contexto internacional marcado por el retroceso de la guerra fría simbolizado para la izquierda en la visita de Jruschov a los Estados Unidos, a la que se sumaba el lanzamiento del primer satélite artificial por la Unión Soviética. Acontecimientos sobrados para que también los comunistas españoles apostaran entonces por la "superioridad del socialismo sobre el capitalismo".

Euforia y firmeza que difícilmente podría tener su correlato a nivel doméstico tras los fracasos del bienio “jornadista». Con todo el congreso no solo ratificó la política de reconciliación sino que se reafirmó en la realización de la ansiada huelga nacional renunciando al llamamiento a fecha fija y apostando por el modelo de la "mancha de aceite» en el que las acciones parciales deberian finalmente coincidir en un paro generalizado. Un planteamiento del conflicto en términos de proceso que andando el tiempo haría suyo la coordinadora estatal de Comisiones Obreras. Un congreso, en fin que se hizo eco de los efectos del programa estabilizador de los tecnócratas no solo sobre la población asalariada sino también sobre capas medias incluyendo entre las víctimas de esa política tildada de caótica a la burguesía "no monopolista». Esto es por la emprendedora, la fracción de clase más dinámica a la que el partido asignaría protagonismo relevante si se distanciaba del régimen y sintonizaba con la oposición política. Y sobre todo que ésta lograra la unidad, incluso si para conseguirla se le exigían al PCE «hacer todas las concesiones necesarias".

La nueva imagen que el PCE trataba de presentar al resto de la oposición le sería encomendada desde entonces a la figura de Santiago Carrillo, el nuevo secretario general elegido en el mismo congreso, mientras Dolores Ibárruri preservaría su prestigio e influencia desde Moscú y el también veterano Vicente Uribe sería arrinconado en París, entre otras razones por su pretensión de emular algunas actitudes estalinistas relacionadas como el culto a la personalidad universalmente aireadas y denunciadas, como es sabido, cuatro años antes en el XX congreso del PCUS. Parecía recuperarse el tan escasamente practicado principio de dirección colectiva, de obligado cumplimiento a partir de entonces cuando tendía a incrementarse la presencia de delegados del interior - en el sexto superaron la veintena, frente a media docena del anterior - y se acababa con "el ordeno y mando s supuestamente ejercido por Uribe más que por ningún otro en el enclave parisino, siendo Santiago Carrillo el mayor damnificado de los camaradas ascendentes. Una práctica nefasta, en cualquier caso, que la diáspora del exilio había propiciado en la cúpula del PCE y también en las de 
otras organizaciones como el clamoroso caso de Rodolfo Llopis en la sede socialista de Toulouse. En fin, un cambio en los métodos de dirección acompañado de objetivos ambiciosos - casi temerarios, cabría decir-al contemplar desde entonces de transformar la organización en un partido de masas, inclusive en la clandestinidad.

En el plano programático, en cambio, se endurecerían las posiciones respecto del anterior al postularse, según las páginas finales de la historia oficial que lograron recogerlo, "líneas de avance hacia el socialismo en una perspectiva del desarrollo democrático" al tiempo que la inercia de nuevo hacía acto de presencia. Una vez más se volvía sobre la necesaria reforma agraria y la supresión de las ya famosas "supervivencias feudales" justamente en el mismo año que las remesas de los emigrantes económicos, en su mayoría procedentes de anteriores jornaleros de la España de la gran propiedad, - a la sazón casi en plena fase de mecanización agrícola - habian superado la cifra de los cincuenta millones de dólares.

Concluido el congreso sin cita ni consigna movilizadora de ámbito nacional que preparar, pero con la nueva dirección convencida de engrosar las filas en la perspectiva del "gran partido de masas" - a la nueva afiliación procedente de la última generación, la del relevo, les encuadraría la Unión de Juventudes Comunistas (UJC) desde 1961 una vez esfumadas las todavía recordadas JSU_ la situación que vivia la militancia no era precisamente para soñar con la consecución de esos objetivos. A corto plazo la iniciativa seguía manteniéndola el régimen de Franco; y el gobierno de los tecnócratas se beneficiaba progresivamente de la coyuntura alcista, de las inversiones de capital extranjero, y las remeses de los emigrantes empezaban a suplir con creces la en realidad cicatera ayuda financiera del gobierno norteamericano derivada del acuerdo militar de 1953.

$Y$ en cuanto al semiparalizado frente obrero, las novedades tampoco dejaban de ser preocupantes para el partido dado que en el mismo año del VI congreso se registrarán dos acontecimientos en los que no tendrá participación. El primero, la constitución de la Unión Sindical Obrera (USO), organización de clase, no amarilla, promovida por católicos e independientes que conocían la táctica comunista de la utilización del Vertical a la que tampoco renunciaban, pero que no hacían de ella premisa central para su proyecto autogestionario. El segundo denotaba peor cariz al tratarse de la formación de una alianza entre UGT, CNT y STV con la consabida exclusión de los comunistas; acuerdo éste que provocó menor pesadumbre en la organización que la repentina autonomía de los católicos de USO, por ofrecer la prueba real de su débil implantación en el movimiento obrero del momento. Si bien el pacto de las siglas sindicales 
históricas, pese a su carácter efímero, significaba la confirmación del casi imposible retorno de la militancia obrera comunista a la UGT, todavía el único referente sindical para los veteranos que aún confiaban en el cambio de táctica que les distanciará ahora. Como les sorprendería menos la actitud de los «meapilas" vascos, que la consolidación del anticomunismo en el sindicalismo anarquista.

De nuevo, pues, en solitario, el PCE proseguirá ensayando la misma táctica de penetración en las instituciones legales, potenciando las informaciones criticas sobre una situación (que económicamente mejoraba) a través de la perenne e infatigable emisora Radio España Independiente, La Pirenaica, y tratando de neutralizar actitudes derrotistas que nutrían el nuevo discurso del resto de la oposición exterior según el cual no cabía otra alternativa al régimen que esperar la desaparición física del dictador para la restauración de la democracia.

En esta tesitura, cabria decir, sorprendería a tirios y troyanos, tanto al gobierno como al conjunto de la oposición, los efectos inmediatos provocados por uno de los muchos pequeños conflictos registrados en la cuenca minera asturiana en los meses que precedieron a la primavera de 1962 , a saber: el despido en el mes de abril de siete picadores de la mina Nicolasa que llevaría a movilizar en pocas semanas a una cifra de trabajadores estimada entre 200.000 y 400.000 según las estimaciones más ponderadas; ,en cualquier caso la mayor registrada desde la guerra civil, nutrida principalmente por huelguistas asturianos, vascos, y catalanes. Una muestra reveladora de cómo en un contexto patronal prepotente, la indisciplina laboral de una minoría de operarios - sobre todo si desempeñan labores extractivas como era el caso de los picadores - a causa de la negativa de la empresa a mejorar el trabajo a destajo provocó la paralización semiforzada del resto de los operarios de la mina y la solidaridad con estos del resto de los trabajadores de las cuencas, primero la del Cudal y después la del Nalón. Y desde la perspectiva de la oposición verificar cómo la protección policial de la producción hullera posibilitó el desbordamiento de comunistas y católicos, pese a la actividad política que desempeñaron en el sector. Proceso que el comité regional de los comunistas asturianos reunido en noviembre del mismo año se negó a reconocer en la cuestión referida al "arranque" espontáneo de la huelga en función de trabajo previo realizado por los correspondientes responsables del sector, según el informe que hizo a la dirección del partido. No planteará problemas de competencia, en cambio, la posterior actividad coordinadora desplegada por todos, tarea en la que también participaron los socialistas, ni la propagación fuera de Asturias del conflicto a cargo principalmente de los comunistas, el partido de mayor implantación a escala nacional. 
Especial importancia la adquirida por la coordinación y mantenimiento de la huelga, entre otros motivos por permitir una insólita cobertura informativa, sobre todo la de los corresponsales y enviados especiales de la prensa extranjera desde que se especuló en los medios de comunicación con la relación entre el estallido minero y "el principio del fin» de la dictadura franquista en base a la firmeza reivindicativa, aunque básicamente económica, de los miles de huelguistas. Incidencia de los medios de comunicación sobre todo en el deterioro de la imagen del régimen en el momento que proyectaba abrirse a Europa al optar de nuevo por la represión a todos los niveles. Ejercicio éste practicado con la dureza acostumbrada a escala nacional, excepto en Asturias donde a consecuencia de reanudarse y prolongarse la conflictividad hasta el año siguiente, se experimentarian nuevos métodos de control. Para los varones, además despidos laborales y detenciones convencionales, deportación a las provincias menos conflictivas de la España agraria de más de un centenar de mineros (124); para el radicalismo obrero de las mujeres más activas de las cuencas el humillante castigo de corte de pelo aplicado a tres de ellas (Anita Sirgo, Constantina Pérez, y Celestina Marrón) por haber incitado al paro.

Vejaciones infligidas a instancia del capitán de la guardia civil, el malagueño Antonio Caro, que provocarán la redacción de escrito de protesta firmado por un gran número de intelectuales encabezado por Ramón Menéndez Pidal, director entonces de la Real Academia de la Lengua. Denuncia que alcanzó gran difusión y preocupación al gobierno -pese a que según el entonces ministro aperturista, Manuel Fraga, se trataba de cuna simple tomadura de pelo" que se sumaba a la previa solidaridad manifestada por sacerdotes de las cuencas y las instituciones eclesiales del apostolado seglar que la prensa de la época ya tenía dificultades para silenciar.

Pero aunque para el gobierno las huelgas de la primavera de 1962 habian sido provocadas por "los cabecillas comunistas" - y en condición de tales fueron encarcelados doce trabajadores, siendo las mujeres rapadas esposas de mineros militantes del PCE domiciliados en las cuencas-, la principal contribución del PCE lo fue al mantenimiento y extensión del conflicto, como antes indicamos. Una actividad en la que paradójicamente se certificaba la defunción del "entrismo" estaliniano, en la medida que era superada en eficacia por las comisiones obreras surgidas a lo largo y ancho del conflicto. Una alternativa consistente en la organización sencilla e informal de trabajadores surgida para reivindicar mejoras convenidas —eso sí, al margen del vertical y del reglamento vigente- en la que algunos comunistas habian participado e incluso promovido a partir de 1956 (como la de la mina La Camocha, en enero de 1957, y alguna otra), pero hacia las que la mayoría de la militancia comunista había mostrado, sino rechazo sí indiferencia, 
principalmente los dirigentes. No sólo por la lógica pluralidad ideológica de origen y la informalidad funcional sino, en especial, por la inestabilidad que las caracterizaba.

Fue así como las huelgas del bienio 1962-63 constituyeron una experiencia propicia para corregir las carencias que los comunistas achacaban a las comisiones. Podían surgir, funcionar y desaparecer en las fábricas, efectivamente, pero su flexibilidad era tal que también era factible su constitución fuera y desde fuera por los militantes del partido para actuar en los centros de trabajo y en los locales de la organización sindical. Y por supuesto estar presentes en la negociación de los convenios, participar en las elecciones sindicales para lograr puestos de enlaces y de jurados de empresa; en fin resuitar tan polivalentes como para defender no sólo los intereses de los trabajadores en activo, sino también los de los despedidos, como hicieron los metalúrgicos vascos entonces al nivel de Vizcaya, e incluso para negociar el retorno de los sancionados con el destierro, como la que acordaron los mineros deportados asturianos después de la huelga de 1962.

En cualquier caso entre el reciente entusiasmo de la inmensa mayoría por las Comisiones y la actitud de quienes en el partido se resistian a archivar la OSO, en algún caso se presentará la nueva fase como resultante de una supuesta síntesis entre las dos tácticas bajo la rebuscada sigla de Oposición Sindical de Comisiones Obreras. De ahi que los comunistas españoles encontrarán en las Comisiones no sólo la principal fuente de afiliación y la tabla de salvación que les permitirá salir a la superficie tras los reiterados intentos de "entrar» en fábricas ( $y$ minas) y las fallidas experiencias urbanas de las citadas jornadas por la reconciliación, además de disponer del instrumento político más eficaz contra la dictadura y de mayor vigor para el cambio social de entre los sindicatos existentes.

Así lo debió percibir dirección y militancia informada cuando poco después de concluida la primera fase de las huelgas del 62, el partido de nuevo era el único excluido, junto con los anarquistas, del "contubernio» de Munich para los franquistas organizado para impedir el ingreso de la España no democrática en la Comunidad Económica Europea. Porque no consta que se registraran frustraciones comparables a las producidas por los repetidos aislamientos anteriores por saberse participantes en el movimiento emergente de las Comisiones, e incluso respaldados por el aún minoritario, pero dinámico sector de las "fuerzas de la cultura". Sería desde este ambiente universitario de donde procedería la frase «PCE, masculino singular» que se difundió en aigunas facultades de Filología a comienzos de los sesenta justamente cuando se iniciaba la ofensiva final contra la dictadura franquista. 